\title{
A Rapid and Sensitive UPLC-MS/MS Method for the Determination of Adefovir in Human Plasma: Application to a Pharmacokinetic Study
}

\author{
Nasr AA ${ }^{1^{*}}$, Abo-Aly MM$^{2}$, Makram $\mathrm{TS}^{3}$ and Alzoubi $\mathbf{M I}^{\mathbf{1}}$ \\ 1 International Centre for Bioavailability, Pharmaceutical and Clinical Research, Obour City, Egypt \\ ${ }^{2}$ Chemistry Department, Faculty of science, Ain Shams University, Cairo, Egypt \\ ${ }^{3}$ Faculty of pharmacy, 6 October University, 6 October City, Egypt
}

\begin{abstract}
A sensitive, rapid and selective liquid chromatography-tandem mass spectrometric (UPLC-MS/MS) analytical method based on protein precipitation was developed and validated for analysis of Adefovir in human plasma. Adefovir-d4 was used as an internal standard and Waters X-Select HSS T3-C18 $(3.0 \times 50 \mathrm{~mm}, 2.5 \mu \mathrm{m})$ column provided the desired chromatographic separation of compounds followed by detection with mass spectrometry. The method used simple isocratic chromatographic condition and mass spectrometric detection in the positive ionization mode. The calibration curves were linear over the range of $1.00 \mathrm{ng} / \mathrm{mL}$ to $30.00 \mathrm{ng} / \mathrm{mL}$ with the lower limit of quantitation validated at $1.00 \mathrm{ng} / \mathrm{mL}$. The degree of matrix effect for Adefovir was determined in six different sources of human plasma was $5.23 \%$ and had no impact on study samples analysis with the shortest runtime obtained (1.5 min). The intra- and inter-day precision values were within $2.37 \%$ and $7.87 \%$, respectively, for Adefovir at the lower limit of quantification level. The method described here was successfully applied for the evaluation of pharmacokinetic profiles of Adefovir after single oral administration doses of $10 \mathrm{mg}$ Adefovir dipivoxil to 28 healthy volunteers.
\end{abstract}

Keywords: Adefovir; Liquid chromatography; Tandem mass spectroscopy; UPLC-MS/MS; Pharmacokinetic study; Bioequivalence study

\section{Introduction}

Adefovir, an acyclic phosphonate analog of deoxynucleoside mono-phosphate (IUPAC name: $\{[2-(6-$ amino-9H-purin-9-yl) ethoxy] methyl\} phosphonic acid, PMEA), is a broad spectrum antiviral agent acting as a DNA polymerase inhibitor [1]. It has activity against herpes virus (Epstein-Barr) and retroviruses including the human immunodeficiency virus (HIV) [1]. Adefovir is largely used to treat chronic hepatitis B in adults, though the drug is reported for poor oral bioavailability [2]. The oral bioavailability of Adefovir has been substantially improved by using the bis-pivaloyloxymethyl ester of Adefovir (bis-POM PMEA, Adefovir dipivoxil (Figure 1) as a pro-drug with enhanced lipophilicity and achieving higher systemic Adefovir levels. Adefovir dipivoxil spontaneously hydrolyzes to mono-POMPMEA, which is rapidly converted into PMEA (Adefovir) by enzyme. Adefovir is an acyclic nucleoside analog of adenosine monophosphate which is phosphorylated to the active metabolite Adefovir diphosphate by cellular kinases [2].

Although several methods have been reported to quantify Adefovir in human plasma [3-6] including serum [7], by employing liquid chromatography-tandem mass spectrometry (LC-MS/MS), analytical limitations could not be overcome. The published methods demonstrated LC-MS/MS method for Adefovir estimation but lacked sensitivity and

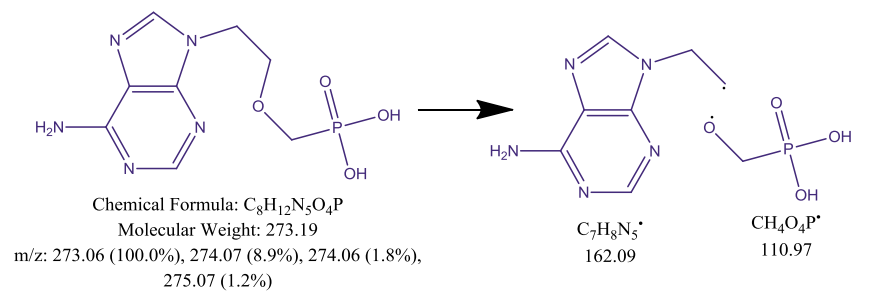

Figure 1: Chemical Structure of Adefovir and its fragments. had lengthy runtime [5,7]. Xie et al. [6] developed a LC-MS/MS method for the determination of Adefovir with limit of quantitation $0.5 \mathrm{ng} / \mathrm{mL}$ but this method had matrix related issue.

The reported method failed to use labeled/deuterated analog of Adefovir for estimation from plasma to compensate equivalent matrix effect with that of analyte. Vela et al. [8] had developed an LC-MS/MS method using a very tedious and complexion-pairing technique for Adefovir estimation. An interesting LC-MS/MS method of Adefovir had been reported with emphasis on hydrophilic interaction but it failed to achieve lower limit of quantification (LOQ) $1.00 \mathrm{ng} / \mathrm{mL}$ [9]. Moreover, Chen et al. [10] and Goswami et al. [11] achieved sensitivity $0.25 \mathrm{ng} /$ $\mathrm{mL}$ and $0.5 \mathrm{ng} / \mathrm{mL}$, respectively, But the methods had lengthy analysis runtime ( $>7 \mathrm{~min}$ ) and $(4.5 \mathrm{~min})$, respectively (Figure 1 ).

Bioavailability/bioequivalence studies are frequently conducted on healthy volunteers with Adefovir dipivoxil 10 or $20 \mathrm{mg}$ tablet, marketed as Hespera (Gilead Sciences, Inc., Foster City, CA). Regulatory guidance $[12,13]$ suggests that LOQ should be sufficient to characterize pharmacokinetic parameters based on expected peak plasma concentration (Cmax). European Medicine Agency [13] suggests 5\% of Cmax should be achieved to have sufficient sensitivity to capture profile in elimination phase of a drug. Amonograph on Adefovir states that the following oral administration of a $10 \mathrm{mg}$ single dose of Hespera in

*Corresponding author: Nasr AA, International Centre for Bioavailability, Pharmaceutical and Clinical Research, Obour City, Egypt, Tel: +213 21661893 E-mail: ahmed.mostafa.azab@gmail.com

Received September 12, 2017; Accepted September 29, 2017; Published October 05, 2017

Citation: Nasr AA, Abo-Aly MM, Makram TS, Alzoubi MI (2017) A Rapid and Sensitive UPLC-MS/MS Method for the Determination of Adefovir in Human Plasma: Application to a Pharmacokinetic Study. J Bioequiv Availab 9: 530-535. doi: $10.4172 / j b b .1000358$

Copyright: (c) 2017 Nasr AA, et al. This is an open-access article distributed unde the terms of the Creative Commons Attribution License, which permits unrestricted use, distribution, and reproduction in any medium, provided the original author and source are credited. 
chronic hepatitis B patients, the mean Cmax was $18.4 \mathrm{ng} / \mathrm{mL}$ with mean elimination half-life of $7.48 \mathrm{~h}$ [14]. But, published literature reflected high variation ( $14.9 \mathrm{ng} / \mathrm{mL}$ to $29.7 \mathrm{ng} / \mathrm{mL}$ ) in mean Cmax for $10 \mathrm{mg}$ Adefovir tablet, though administered to healthy volunteers $[5,10]$. Such variation could be attributed to matrix effect or any other aspects of method limitations. Therefore, it becomes imperative to develop a precise, accurate, and high throughput method for estimation of Adefovir in human plasma. For conducting the bioequivalence study on Adefovir (i.e. $10 \mathrm{mg}$ Hespera tablet), method sensitivity should be such that concentration profile up to $36 \mathrm{~h}$ ( 5 half-lives) could be plotted. Though $1.0 \mathrm{ng} / \mathrm{mL}$ LOQ could have sufficed [13] to characterize pharmacokinetic parameter, we further decreased method sensitivity to this concentration. In the present study, a systematic evaluation of matrix interference was investigated by using protein precipitation extraction (PPE) followed by a cleaning step. The combination technique was used to bring down matrix effect below $6 \%$ level effectively. The unique method highlights Adefovir stability as well as selectivity in blank (untreated) plasma, hemolyzed and lipemic plasma samples. The method had been successfully applied to clinical sample analysis.

\section{Experimental}

\section{Chemicals and reagents}

Working standards of Adefovir (Purity=98.0\%) and Adefovir- $\mathrm{d}_{4}$ (deuterium labeled Adefovir, purity $=98.0 \%$ ) were procured from Hetero Corporate, Telangana, India, and Toronto Research Chemicals, Canada, respectively. Acetic acid, ammonium acetate and ammonia solution were Fisher (Analysis grade), methanol is Fisher (gradient grade). Acetonitrile and Dichloromethane were Sigma (gradient grade). De-Ionized ultrapure water was obtained by using a Milli-Q device (Millipore, Cairo, Egypt). Drug-free (blank) human plasma containing K3EDTA (ethylene-diaminetetraacetic acid tripotassium salt), as anticoagulant, was obtained from the subjects who have participated in clinical studies.

\section{Preparation of standards and quality control samples}

The stock solutions of Adefovir were prepared by dissolving the accurately weighed reference compound in methanol to give a final concentration of $100.00 \mu \mathrm{g} / \mathrm{mL}$. Two separate stock solutions of Adefovir were prepared for bulk spiking of calibration standards and quality control (QC) samples. Primary dilutions and working standard solutions were prepared from stock solutions using methanol to obtain standard working solutions at concentrations of $0.1,0.2,0.4$, $0.6,1.0,1.6,2.2$ and $3.0 \mu \mathrm{g} / \mathrm{mL}$, which used for spiking the calibration standards. However, concentrations $0.3,1.2$ and $2.4 \mu \mathrm{g} / \mathrm{mL}$ were used for spiking QC samples. The stock solution of the internal standards (IS) was prepared by dissolving the accurately weighed the standard of Adefovir- $\mathrm{d}_{4}$ in methanol to give a final concentration of $96.0 \mu \mathrm{g} / \mathrm{mL}$, then a diluted solution was prepared of concentration $96.0 \mathrm{ng} / \mathrm{mL}$. All the solutions were stored at $4^{\circ} \mathrm{C}$ and were brought to room temperature before use. Eight-point calibration standards and QC samples were prepared by spiking the blank human plasma with appropriate concentration of Adefovir. Calibration standards samples were prepared at concentrations of 1.0, 2.0, 4.0, 6.0, 10.0, 16.0, 22.0 and $30.0 \mathrm{ng} / \mathrm{mL}$. $\mathrm{QC}$ samples $\left(\mathrm{QC}_{\mathrm{L}}, \mathrm{QC}_{\mathrm{M}}\right.$ and $\left.\mathrm{QC}_{\mathrm{H}}\right)$ were prepared at concentrations of $3.0,12.0$ and $24.0 \mathrm{ng} / \mathrm{mL}$, respectively. The spiked Calibration standards and QC samples were stored at $-80^{\circ} \mathrm{C}$.

\section{Plasma sample preparation}

$250 \mathrm{~mL}$ of plasma samples were pipetted into disposable Eppendorf tubes and $50 \mu \mathrm{L}$ of IS working solution $(96.0 \mathrm{ng} / \mathrm{mL}$ of IS) was added.
Vortex for $30 \mathrm{~s}$ and leave samples for $5.0 \mathrm{~min}$. Samples were pretreated with $200 \mu \mathrm{L}$ of $10 \%$ acetic acid and vortex the samples for 30 s. Precipitate with $500 \mu \mathrm{L}$ of acetonitrile then vortex for $30 \mathrm{~s}$, and centrifuge the samples for $10 \mathrm{~min}$ at $4000 \mathrm{rpm}$. Decant $700 \mu \mathrm{L}$ of supernatant in new labeled Eppendorf tubes. Add $700 \mu \mathrm{L}$ of dichloromethane then vortex for $30 \mathrm{~s}$ and centrifuge samples for $10 \mathrm{~min}$ at $4000 \mathrm{rpm}$ then decant from upper layer (aqueous) $200 \mu \mathrm{L}$ in new labeled tubes. Evaporate the samples in concentrator for $10 \mathrm{~min}$ at $60^{\circ} \mathrm{C}$ to get rid of traces dichloromethane. Transfer samples to auto-sampler racks and inject $10 \mu \mathrm{L}$.

\section{UPLC-MS/MS instrumentation and analytical conditions}

Liquid chromatography was performed on an Acquity H-Class ultra-performance liquid chromatography (UPLC) unit (Waters Corp., USA) comprising Acquity UPLC Pump with Quaternary solvent manager, a cooling auto-sampler, a column oven of temperature control. Chromatographic separations were achieved on Waters X-Select HSS T3-C18 $(3.0 \times 50 \mathrm{~mm}, 2.5 \mu \mathrm{m})$ column using a mobile phase mixture of $0.025 \mathrm{M}$ ammonium acetate buffer and $2 \%$ ammonia in methanol $(90: 10, \mathrm{v} / \mathrm{v})$, at isocratic flow rate of $0.5 \mathrm{~mL} / \mathrm{min}$. The column and autosampler temperature were kept at $40^{\circ} \mathrm{C}$ and $8^{\circ} \mathrm{C}$, respectively. XEVO TQ-MS/MS triple quadruple mass spectrometer equipped with an electro-spray ionization (ESI) source, which was operated in positive ion mode. Quantification was carried out using multiple reactions monitoring (MRM) mode of the transitions m/z 274.04>162.09 and 278.04>166.09 for Adefovir and Adefovir-d4, respectively. Dwell time was set at $36 \mathrm{~ms}$ for Adefovir and IS. Nitrogen was used as the nebulizer, auxiliary, collision and curtain gas. The source parameters of the mass spectrometer were optimized and maintained as follows: Capillary: 1.5 $\mathrm{KV}$, cone: $35 \mathrm{~V}$, collision energy: $28 \mathrm{eV}$, source temp.: $150^{\circ} \mathrm{C}$, desolvation gas: $800 \mathrm{~L} / \mathrm{H}$, desolvation temp.: $300^{\circ} \mathrm{C}$, collision gas flow: $0.15 \mathrm{~mL} / \mathrm{min}$ (Figure 2).

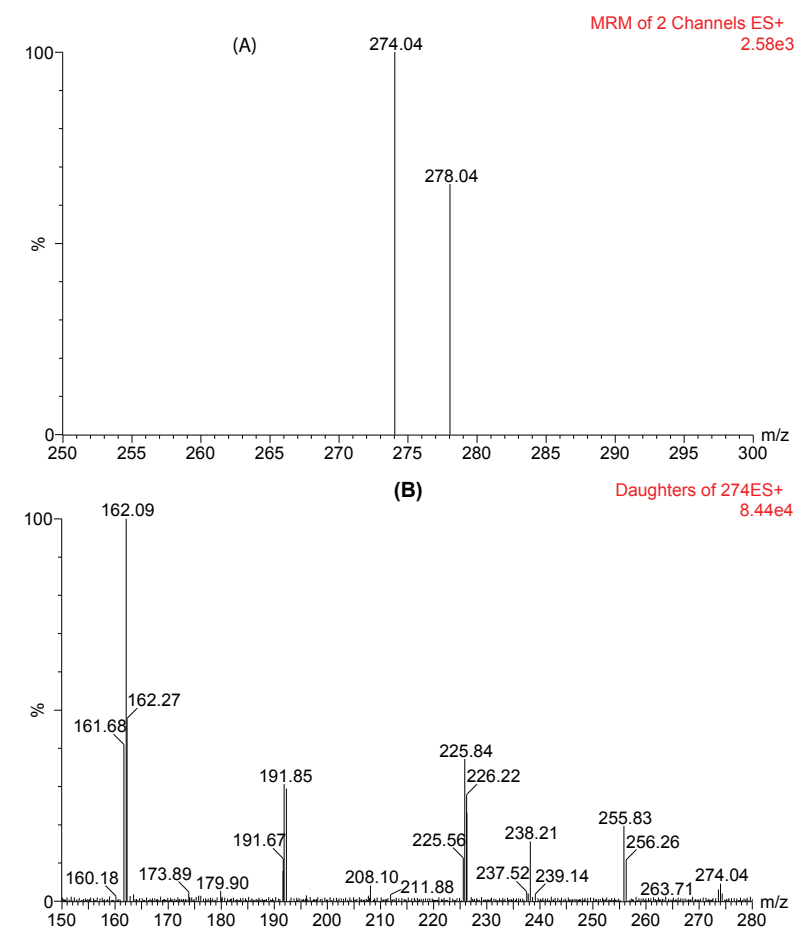

Figure 2: (A) Mass spectrum for Adefovir and Adefovid- $d_{4}$ in the positive ESI mode; (B) MS/MS product ion spectrum of $[\mathrm{M}+\mathrm{H}]^{+}$of Adefovir at $\mathrm{m} / \mathrm{z} 274.04$ as the precursor ion. 
Citation: Nasr AA, Abo-Aly MM, Makram TS, Alzoubi MI (2017) A Rapid and Sensitive UPLC-MS/MS Method for the Determination of Adefovir in Human Plasma: Application to a Pharmacokinetic Study. J Bioequiv Availab 9: 530-535. doi: 10.4172/jbb.1000358

\section{Method validation}

Method validation of Adefovir in human plasma was carried out, following US Food and Drug Administration guidelines and Guidance from European Medicine Agency [12,13]. The method was validated for selectivity, sensitivity and carry over, linearity, precision and accuracy, recovery, matrix effect, re-injection reproducibility, dilution integrity and stability of Adefovir during both short-term sample processing and long-term storage.

Selectivity: The selectivity of the method towards endogenous plasma matrix components, and concomitant medications was assessed in six different sources of blank plasma samples; these were collected under controlled conditions to simulate the plasma matrix harvested from participants. These samples were processed using the proposed extraction protocol and analyzed with the set chromatographic conditions at LLOQ level. The peak area of the co-eluting components or interferences in blank sample should be less than $20 \%$ and $5 \%$ from those of the analyte and IS, respectively (Figure 3).

Sensitivity: The procedures adopted for investigating method sensitivity differentiated between two types of sensitivities namely: (A) calibration sensitivity, which was equated with the slope of the calibration graph, and (B) analytical sensitivities $(\gamma)$, which accounted for the variation in the standard deviation of the analytical signal measured for different concentration levels of Adefovir.

Linearity and LLOQ: Six calibration curves were used to demonstrate the linearity of the method. The area ratio responses for (Adefovir/IS) was used for regression analysis. Each calibration curve

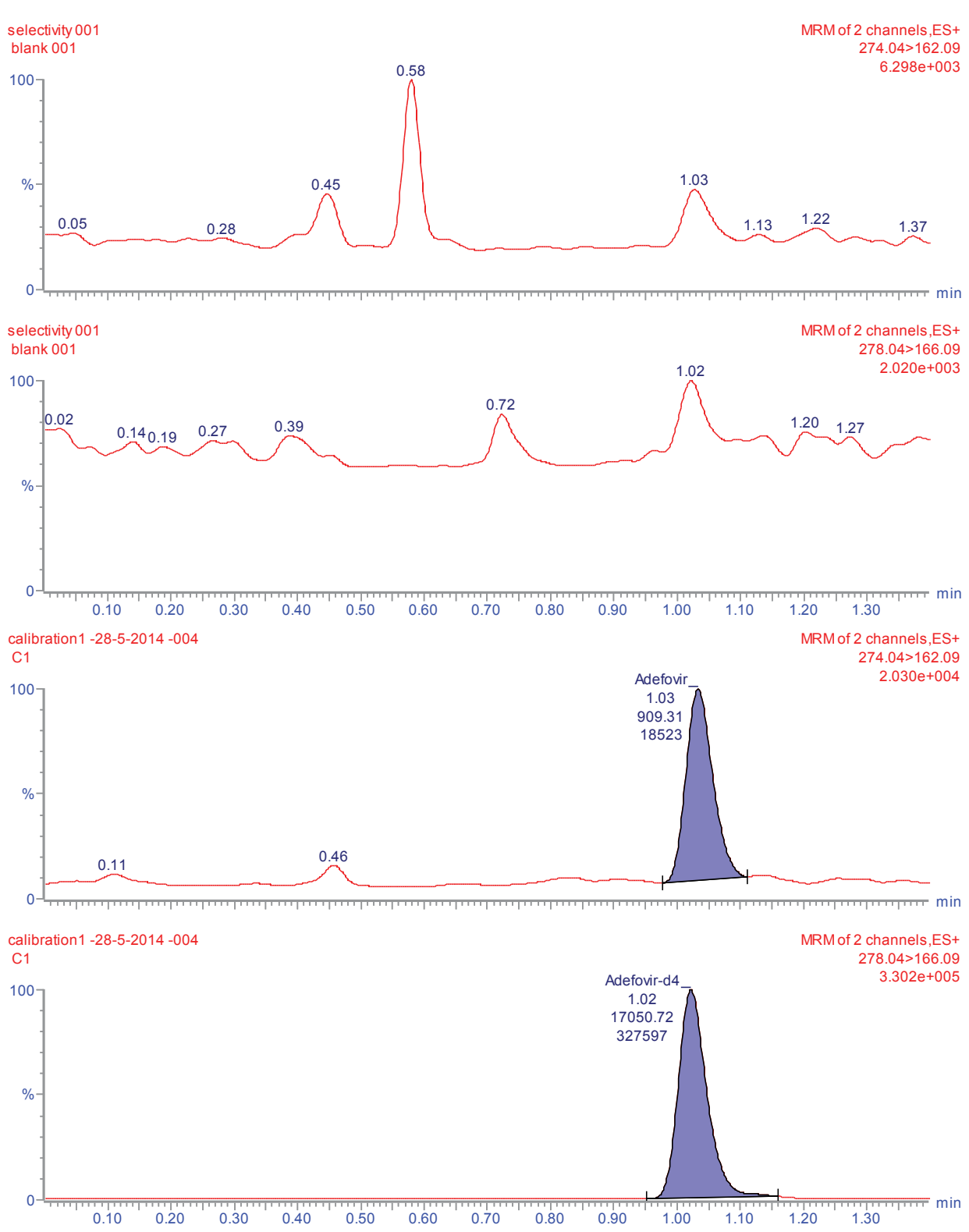

Figure 3: Chromatograms of (a) Drug-free human plasma; (b) Spiked plasma at lower limit of quantitation. 
Citation: Nasr AA, Abo-Aly MM, Makram TS, Alzoubi MI (2017) A Rapid and Sensitive UPLC-MS/MS Method for the Determination of Adefovir in Human Plasma: Application to a Pharmacokinetic Study. J Bioequiv Availab 9: 530-535. doi: 10.4172/jbb.1000358

was analyzed individually by using least square weighted $\left(1 / \mathrm{x}^{2}\right)$ linear regression (obtained by best fit method). Back-calculations were made from these curves to determine the concentration of Adefovir in each calibrator. A correlation coefficient $(r)>0.99$ was desirable for all the calibration curves. In addition, the analyte peak at LLOQ concentration should be identifiable, discrete and reproducible with accuracy within $\pm 20 \%$ and a precision $\leq 20 \%$ whereas other levels of concentration should be $\pm 15 \%$ for accuracy and $\leq 15$ for precision (Table 1 ).

Precision and accuracy: The intra- and inter-day precision and accuracy were performed for Adefovir in human plasma, which determined by replicate analysis of QC samples $(n=6)$ at LLOQ, $\mathrm{QCL}, \mathrm{QCM}$ and QCH. The precision of the method was determined by calculating the percentage coefficient of variation $(\% \mathrm{CV})$ for each level. The deviation at each concentration level from the nominal concentration was expected to be ( $\leq 15 \%)$, excluding at LLOQ level ( $\leq 20 \%)$. Similarly, the mean accuracy should not deviate by $( \pm 15.0 \%)$, excluding at LLOQ level ( $\pm 20 \%)$ (Table 2$)$.

Matrix effect: The matrix effect was estimated by extraction of 6 lots of blank matrix from individual donors. The matrix factor (MF) was estimated by calculating the ratio of the peak area in the presence of matrix (measured by analysing blank matrix spiked after extraction with analyte), to the peak area in absence of matrix (pure solution of the analyte). The IS normalized MF should also be calculated by dividing the MF of the analyte by the MF of the IS. When, IN-NMF=1 indicates no matrix effect, IN-NMF $<1$ indicates ion-suppression and IN-NMF $>1$ indicates ion-enhancement. The CV of the IS-normalized MF calculated from the 6 lots of matrix should not be greater than $15 \%$ (Table 3).

Stability: Primary stock solutions were found to be stable for 151 days. Stock solution stability was studied at two concentration levels and it was found to be $99.23 \%$ to $107.84 \%$.

Results of short-term stability are shown in Table 4. Samples were

\begin{tabular}{|c|c|}
\hline Calibrators and QCs & Adefovir concentrations $\mathbf{( n g} / \mathbf{m L})$ \\
\hline Blank & - \\
\hline$C 1$ & 1 \\
\hline $\mathrm{C} 2$ & 2 \\
\hline $\mathrm{C} 3$ & 4 \\
\hline $\mathrm{C} 4$ & 6 \\
\hline $\mathrm{C} 5$ & 10 \\
\hline $\mathrm{C} 6$ & 16 \\
\hline $\mathrm{C} 7$ & 22 \\
\hline $\mathrm{C} 8$ & 30 \\
\hline $\mathrm{QC}_{\mathrm{L}}$ & 3 \\
\hline $\mathrm{QC}_{\mathrm{M}}$ & 12 \\
\hline $\mathrm{QC}_{\mathrm{H}}$ & 24 \\
\hline
\end{tabular}

Table 1: Concentrations of matrix based calibrators and QCs Samples.

\begin{tabular}{|l|c|c|c|c|}
\hline Precision between the three runs \\
\hline Result & LLOQ & $\mathbf{Q C}_{\mathbf{L}}$ & $\mathbf{Q C}_{\mathbf{M}}$ & $\mathbf{Q C}_{\mathrm{H}}$ \\
\hline Average & 1.055 & 2.8 & 11.994 & 25.463 \\
\hline ST.DEV & 0.083 & 0.142 & 0.626 & 0.759 \\
\hline CV\% & 7.87 & 5.07 & 5.22 & 2.98 \\
\hline Accuracy between the three runs \\
\hline Result & LLOQ & $\mathbf{Q C}_{\mathbf{L}}$ & $\mathbf{Q C}_{\mathrm{M}}$ & $\mathbf{Q C}_{\mathrm{H}}$ \\
\hline Average & 1.055 & 2.8 & 11.994 & 25.463 \\
\hline Error & 0.055 & -0.2 & -0.006 & 1.463 \\
\hline Relative error (\%) & 5.5 & -6.67 & -0.05 & 6.1 \\
\hline
\end{tabular}

Table 2: Between run accuracy and precion. stable under the studied conditions. Three sets of spiked samples with low and high concentrations of the analytes were analyzed and left in the auto-sampler at $8^{\circ} \mathrm{C}$ for one day. The samples were analyzed using a freshly prepared calibration samples. The processed samples were stable at room temperature for this period. The results are shown in Table 4.

The long-term stability of frozen plasma samples was examined after 151 days storage at $-86^{\circ} \mathrm{C}$. The samples were stable under studied conditions as shown in Table 4.

Plasma samples with low, medium and high concentrations of Adefovir were prepared. The samples were stored at $-86^{\circ} \mathrm{C}$ and subjected for 3 freeze/thaw cycles. During each cycle triplicate one $\mathrm{ml}$ aliquots was processed, analyzed and the results averaged. No substance loss during repeated thawing and freezing was observed as shown in Table 4.

\section{Pharmacokinetic Study}

The validated UPLC-MS/MS method was applied to a PK study of Adefovir Dipivoxil (10 mg film-coated tablet), Twenty-Eight Egyptian healthy adult volunteers participated in this study. The volunteers were all adult Egyptians who were selected after completing a thorough medical, biochemical and physical examination. Informed consent was obtained from all subjects after explaining the aims and risks of the study. The study protocol was approved by the Human Investigation Ethical Committee at the Ministry of Health, Egypt.

After an overnight fast $(12 \mathrm{~h})$, the volunteers took the assigned

\begin{tabular}{|c|c|c|}
\hline \multicolumn{3}{|c|}{ IS-Normalized MF } \\
\hline Source & $\mathbf{Q C}_{\mathbf{L}}$ & $\mathbf{Q C}_{\mathbf{H}}$ \\
\hline Source (1) & 1.2022 & 1.0508 \\
\hline Source (2) & 1.2177 & 1.1676 \\
\hline Source (3) & 1.1229 & 1.1331 \\
\hline Source (4) & 1.1446 & 1.1552 \\
\hline Source (5) & 1.1897 & 1.0825 \\
\hline Source (6) & 1.1796 & 1.0277 \\
\hline Average IS-N MF & 1.1761 & 1.1028 \\
\hline ST.DEV IS-N MF & 0.0359 & 0.0577 \\
\hline CV\% & 3.05 & 5.23 \\
\hline
\end{tabular}

Table 3: Matrix effect.

\begin{tabular}{|c|c|c|c|}
\hline Parameters & \multicolumn{3}{|l|}{ Stability\% } \\
\hline $\begin{array}{l}\text { a) Post preparative (Auto- } \\
\text { sampler) stability }\end{array}$ & \multicolumn{2}{|l|}{$0 \mathrm{~h}(\mathrm{RT})$} & $24 \mathrm{~h}(\mathrm{RT})$ \\
\hline$Q C_{L}$ & 92.23 & \multicolumn{2}{|c|}{90} \\
\hline $\mathrm{QC}_{\mathrm{H}}$ & 105.86 & \multicolumn{2}{|c|}{106.93} \\
\hline $\begin{array}{l}\text { b) Matrix based short term } \\
\text { stability }\end{array}$ & $0 \mathrm{~h}(\mathrm{RT})$ & \multicolumn{2}{|c|}{$24 \mathrm{~h}(\mathrm{RT})$} \\
\hline$Q C_{L}$ & 89.93 & \multicolumn{2}{|c|}{86.9} \\
\hline $\mathrm{QC}_{\mathrm{H}}$ & 104.65 & & 103.84 \\
\hline $\begin{array}{l}\text { c) Matrix based long term } \\
\text { stability }\end{array}$ & 0 day & 41 days & 151 days \\
\hline$Q C_{L}$ & 94.7 & 94.13 & 93.13 \\
\hline $\mathrm{QC}_{\mathrm{H}}$ & 96.63 & 99.66 & 95.54 \\
\hline $\begin{array}{l}\text { d) The freeze and thaw } \\
\text { stability }\end{array}$ & Cycle (0) & \multicolumn{2}{|c|}{ Cycle (3) } \\
\hline$Q C_{L}$ & 93.83 & \multicolumn{2}{|c|}{93.23} \\
\hline$Q C_{H}$ & 105.24 & \multicolumn{2}{|c|}{109.36} \\
\hline
\end{tabular}

Table 4: Stability of Adefovir in human plasma by the proposed method. 
Citation: Nasr AA, Abo-Aly MM, Makram TS, Alzoubi MI (2017) A Rapid and Sensitive UPLC-MS/MS Method for the Determination of Adefovir in Human Plasma: Application to a Pharmacokinetic Study. J Bioequiv Availab 9: 530-535. doi: 10.4172/jbb.1000358

tablet orally with $250 \mathrm{~mL}$ of water. The volunteers were treated with an oral dose of $10 \mathrm{mg}$ of Adefovir Dipivoxil, and with $10 \mathrm{mg}$ after a 1-week washout period. Regular standardized low-fat meals were provided until $4 \mathrm{~h}$ after dose administration; water intake was allowed after 2 h. Following drug administration, venous blood samples $(5 \mathrm{~mL})$ were collected into heparinized tubes according to the following schedule: immediately before administration and $0.25 \mathrm{~h}, 0.5 \mathrm{~h}, 0.75 \mathrm{~h}, 1 \mathrm{~h}, 1.25 \mathrm{~h}$, 1.5 h, 1.75 h, 2h, 2.25 h, 2.5 h, 2.75 h, 3 h, 3.5 h, 4 h, 5 h, 6 h, 8 h, 10 h, $12 \mathrm{~h}, 24 \mathrm{~h}, 36 \mathrm{~h}$ and $48 \mathrm{~h}$ after dosing.

Blood samples were centrifuged at $4000 \mathrm{rpm}$ for $10 \mathrm{~min}$ to obtain the plasma. The plasma samples were labeled and kept frozen at $86^{\circ} \mathrm{C}$ until analysis. The plasma concentration of Adefovir vs. time profiles were obtained for each individual subject, and non-compartmental PK parameter calculations were performed using the WinNonLin Program version 2.0. The area under the plasma Adefovir concentration-time curve (AUC) was calculated using the trapezoidal rule extrapolated to infinite time. Cmax was the observed maximum concentration and Tmax was the time to reach the maximum drug concentration.

\section{Bioequivalence Discussion}

Figure 4 shows the mean plasma concentrations of Adefovir, while Table 5 shows the pharmacokinetic parameters of Adefovir following oral administration of one tablet of DOVOCARE $10 \mathrm{mg}$ (test product), and one tablet of HEPSERA $10 \mathrm{mg}$ (reference product). The point estimate of the test formulation to the reference formulation ratios (T/R) for $\mathrm{AUC}_{0-48}$ was 97.54 with $90 \%$ confidence limits $(94.47 \rightarrow 100.72)$. For AUC $_{0 \text {-inf }}$ it was 98.68 with $90 \%$ confidence limits $(95.26 \rightarrow 102.23)$ and for $C_{\max }$ inf was 99.22 with $90 \%$ confidence intervals $(94.78 \rightarrow 103.86)$. The parametric $90 \%$ confidence intervals of the mean values for the test/ reference ratio were, in each case, within the bioequivalence acceptable boundaries of $80.00 \%$ to $125.00 \%$ for the pharmacokinetic parameters $\mathrm{AUC}_{0-48}, \mathrm{AUC}_{0 \text {-inf }}$ and $\mathrm{C}_{\max }$. And the calculated power of the study was $100 \%$. The parametric $90 \%$ confidence intervals of the mean values for the test/reference ratio were, in each case, within the bioequivalence acceptable boundaries of $80.00 \%$ to $125.00 \%$ for the pharmacokinetic parameters $\mathrm{AUC}_{0-48}, \mathrm{AUC}_{0 \text {-inf }}$ and $\mathrm{C}_{\max }$. The difference between means of $\mathrm{T}_{\max }$ is not significant $(\mathrm{P}>0.05)$ with respect to Kruskal Wallis test $[15,16]$.

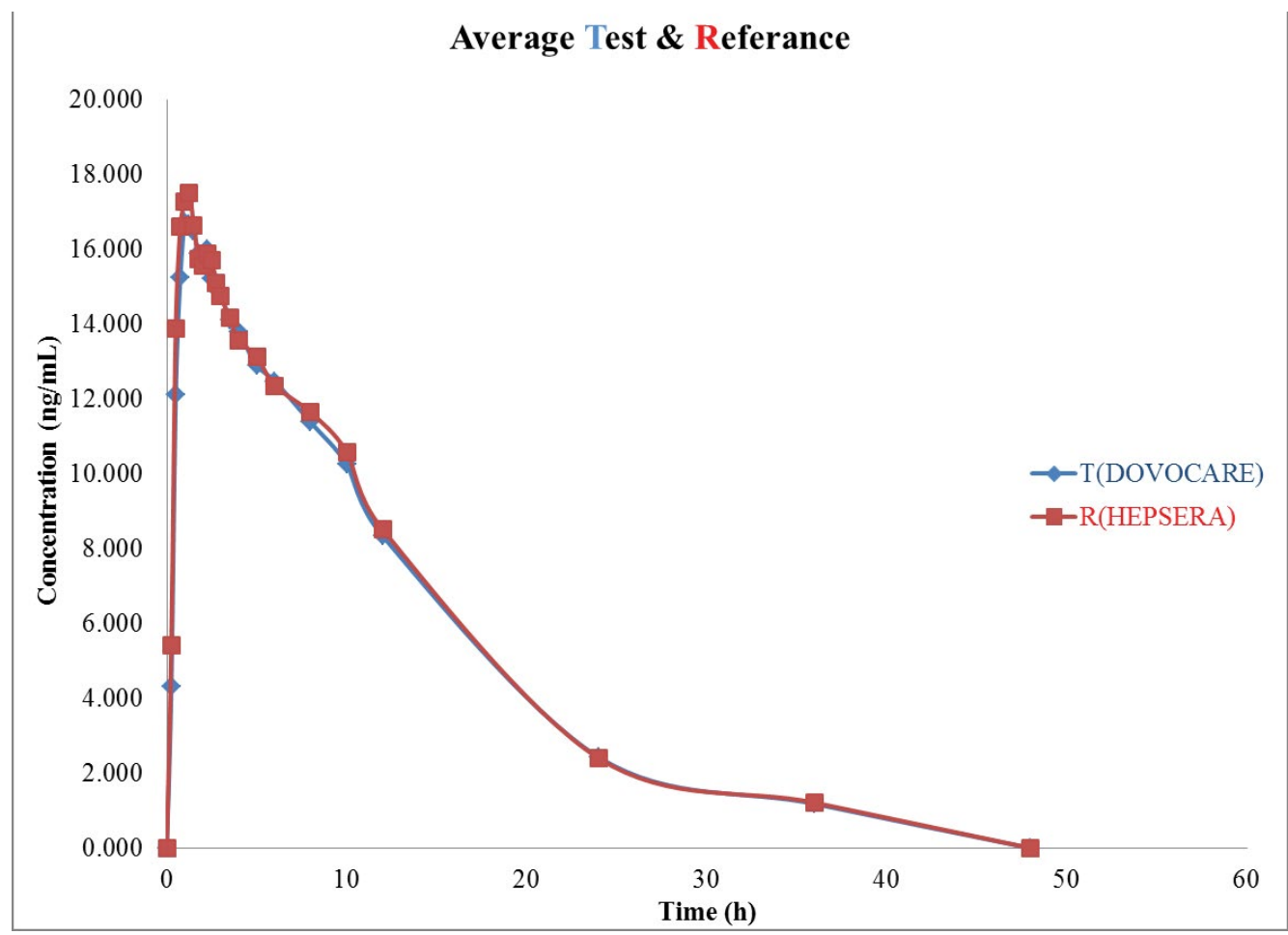

Figure 4: Average plasma concentration ( $\mathrm{ng} / \mathrm{ml}$ ) of Adefovir vs. time (hours) curves following a single dose of $10 \mathrm{mg}$ Adefovir tablet (T: DOVOCARE and R: HEPSERA) based on 28 participants.

\begin{tabular}{|c|c|c|c|c|c|c|c|}
\hline \multirow{2}{*}{ Parameter } & \multirow{2}{*}{$\begin{array}{l}\text { Point estimate (ratio of } \\
\text { geometric mean \%) }\end{array}$} & \multicolumn{2}{|c|}{ Confidence interval } & \multirow{2}{*}{$\begin{array}{c}\begin{array}{c}\text { Confidence } \\
\text { level }\end{array} \\
(1-2 a) \%\end{array}$} & \multicolumn{2}{|c|}{ Standard bioequivalence limit } & \multirow{2}{*}{ Conclusion } \\
\hline & & Lower limit $\%$ & Upper limit\% & & Lower limit $\%$ & Upper limit\% & \\
\hline$A \cup C_{0 \circledast \text { last }}$ & 97.544 & 94.471 & 100.718 & 90 & 80 & 125 & BE \\
\hline$A \cup C_{0 \text {-inf }}$ & 98.68 & 95.257 & 102.227 & 90 & 80 & 125 & BE \\
\hline $\mathrm{C}_{\max }$ & 99.215 & 94.778 & 103.859 & 90 & 80 & 125 & BE \\
\hline
\end{tabular}

Table 5: Confidence interval for the ratio of geometric mean $(\mu \mathrm{T} / \mu \mathrm{R})$. 
Citation: Nasr AA, Abo-Aly MM, Makram TS, Alzoubi MI (2017) A Rapid and Sensitive UPLC-MS/MS Method for the Determination of Adefovir in Human Plasma: Application to a Pharmacokinetic Study. J Bioequiv Availab 9: 530-535. doi: 10.4172/jbb.1000358

The results of this bioequivalence study showed the equivalence of the two studied products in terms of the rate of absorption as indicated by $\mathrm{T}_{\max }$ and $\mathrm{C}_{\max }$ and in terms of the extent of absorption as indicated by $\mathrm{AUC}_{0-48}$ and $\mathrm{AUC}_{0 \text {-inf }}$ (Figure 4 and Table 5).

\section{Conclusion}

In summary, a rapid, specific, reproducible, high-throughput and sensitive UPLC-MS/MS method allows determination of Adefovir using Adefovir-d4 as an internal standard was developed and validated.

Overall the developed method presented adequate sensitivity, excellent selectivity and desired reproducibility for the quantification of Adefovir in human plasma. The other major advantage of this validated method is the shorter runtime of $1.5 \mathrm{~min}$, allowing the quantitation of over 500 samples per day. Moreover, the low limit of quantitation (1 ng/ $\mathrm{ml}$ ), the low matrix effect, the precision and accuracy of the method and also the stability are well within the limits required for bioanalytical assays. In addition, the ISR result with $96.64 \%$ at the end of the study further added strength to our current method.

All these advantages would make it efficient for routine therapeutic drug monitoring as well as for the analysis of large number of plasma samples obtained from exploratory pharmacokinetic studies.

\section{Acknowledgment}

The authors wish to acknowledge the support and facilities received from International Centre for Bioavailability, Pharmaceutical and Clinical Research (ICBR), Egypt, for carrying out this work.

\section{References}

1. Cundy KC (1999) Clinical pharmacokinetics of the antiviral nucleotide analogues Cidofovir and Adefovir. Clin Pharmacokinet 36: 127-143.

2. Qaqish RB, Mattes KA, Ritchie DJ (2003) Adefovir dipivoxil: A new antiviral agent for the treatment of hepatitis B virus infection. Clin Ther 25: 3084-3099.

3. Kearney BP, Ramanathan S, Cheng AK, Ebrahimi R, Shah J (2005) Systemic and renal pharmacokinetics of Adefovir and Tenofovir upon coadministration. J Clin Pharmacol 45: 935-940.
4. Lecompte S, Furtado M, Hardy A (2004) Quantitative determination of Adefovir in human plasma using LC/MS/MS. APPS 1: 608.

5. Bi HC, Zhong GP, Zhou S, Chen X, Huang M (2005) Determination of Adefovir in human plasma by liquid chromatography/tandem mass spectrometry: Application to a pharmacokinetic study. Rapid Commun Mass Spectrom 19: 2911-2917.

6. Xie HT, Wang GJ, Xu MJ, Jia YW, Li H, et al. (2010) A new LC-MS-MS method for quantitative analysis of Adefovir, and its use for pharmacokinetic studies in healthy Chinese volunteers. Chromatographia 71: 587-593.

7. Sun D, Wang H, Wang B, Xiao QQ, Yang J (2006) Development and validation of a sensitive LC-MS/MS method for the determination of Adefovir in human serum and urine. J Pharm Biomed Anal 42: 372-378.

8. Vela JE, Olson LY, Huang A, Fridland A, Ray AS (2007) Simultaneous quantitation of the nucleotide analog Adefovir, its phosphorylated anabolites and 2'-deoxyadenosine triphosphate by ion-pairing LC/MS/MS. J Chromatogr B Analyt Technol Biomed Life Sci 848: 335-343.

9. Xiong Z, Zhang Y, Qin F, Qin T, Yang S, et al. (2010) Hydrophilic interaction liquid chromatography-tandem mass spectrometry for the determination of Adefovir in human plasma and its application to a pharmacokinetic study. $\mathrm{J}$ Chromatogr B Analyt Technol Biomed Life Sci 878: 2111-2116.

10. Chen X, Liu D, Zhu L, Xiao QQ, Yang J (2005) Development and validation of a liquid chromatography/tandem mass spectrometry procedure for the quantification of Adefovir in human plasma. Rapid Commun Mass Spectrom 19: 1893-1898.

11. Goswami D, Gurule S, Saha A (2015) Liquid chromatography-tandem mass spectrometry method for the estimation of Adefovir in human plasma: Application to a pharmacokinetic study. J Pharm Anal 5: 190-199.

12. https://www.federalregister.gov/documents/2013/09/13/2013-22309/draftguidance-for-industry-on-bioanalytical-method-validation-availability

13. http://www.ema.europa.eu/docs/en_GB/document_library/Scientific_ guideline/2011/08/WC500109686.pdf

14. http://www.rxlist.com/hepsera-drug/clinical-pharmacology.htm

15. Goswami D, Khuroo A, Gurule S, Modhave Y, Monif T (2011) Controlled ex vivo plasma hydrolysis of valaciclovir to acyclovir demonstration using tandem mass spectrometry. Biomed Chromatogr 25: 1189-1200.

16. Goswami D, Saha A, Gurule S, Khuroo A, Monif T, et al. (2012) Metaxalone estimation in biological matrix using high-throughput LC-MS/MS bioanalytical method. J Chromatogr B Analyt Technol Biomed Life Sci 902: 132-136. 